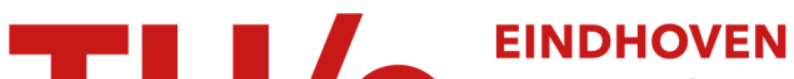 UNIVERSITY OF TECHNOLOGY
}

\section{Reviewing regulatory focus based on four regulatory forms}

Citation for published version (APA):

Chen, Y., \& Bei, L. (2017). Reviewing regulatory focus based on four regulatory forms. Review of General Psychology, 21(4), 354-371. https://doi.org/10.1037/gpr0000133

DOI:

10.1037/gpr0000133

Document status and date:

Published: 01/12/2017

\section{Document Version:}

Accepted manuscript including changes made at the peer-review stage

\section{Please check the document version of this publication:}

- A submitted manuscript is the version of the article upon submission and before peer-review. There can be important differences between the submitted version and the official published version of record. People interested in the research are advised to contact the author for the final version of the publication, or visit the $\mathrm{DOI}$ to the publisher's website.

- The final author version and the galley proof are versions of the publication after peer review.

- The final published version features the final layout of the paper including the volume, issue and page numbers.

Link to publication

\section{General rights}

Copyright and moral rights for the publications made accessible in the public portal are retained by the authors and/or other copyright owners and it is a condition of accessing publications that users recognise and abide by the legal requirements associated with these rights.

- Users may download and print one copy of any publication from the public portal for the purpose of private study or research.

- You may not further distribute the material or use it for any profit-making activity or commercial gain

- You may freely distribute the URL identifying the publication in the public portal.

If the publication is distributed under the terms of Article $25 \mathrm{fa}$ of the Dutch Copyright Act, indicated by the "Taverne" license above, please follow below link for the End User Agreement:

www.tue.nl/taverne

Take down policy

If you believe that this document breaches copyright please contact us at:

openaccess@tue.nl

providing details and we will investigate your claim. 


\title{
Reviewing the Regulatory Focus Based on Four Regulatory Forms
}

\author{
Yu-Shan Athena Chen ${ }^{1}$ and Lien-Ti Bei ${ }^{2}$ \\ ${ }^{1}$ Department of Industrial Design, Eindhoven University of Technology \\ ${ }^{2}$ Department of Business Administration, National Chengchi University
}

\begin{abstract}
This study employs the four regulatory forms (goal pursuit, goal maintenance, negative escape, and active avoidance), to illuminate the heterogeneousness among regulatory focus measurements and activations. The first two studies consistently found that promotion focus involves goal pursuit orientation; however, prevention focus encompasses a goal maintenance and a negative escape orientation. The regulatory forms were then applied to regulatory fit research to investigate how the matches of regulatory forms determine the effect sizes of regulatory fit. By meta-analyses, the weak effect in one-third of regulatory fit studies, whose regulatory forms were mismatched or partially matched, decreased the overall fit effect and increased the heterogeneousness among regulatory fit studies. However, a strong and consistent regulatory fit effect was found in wellmatched of regulatory forms. By examining and extending regulatory forms to measurement, activation and regulatory fit studies, this paper offers further understanding of the mechanisms of regulatory focus.
\end{abstract}

Keywords: regulatory form, regulatory focus, meta-analysis 


\section{Reviewing Regulatory Focus Based on Four Regulatory Forms}

Regulatory focus theory (Higgins, 1997) distinguishes between two regulatory systems. The systems differ in what fundamentally motivates (nurturance versus security) and in what regulatory actions are preferred (approaching versus avoiding). The promotion focus regulates nurturance needs and is concerned with growth, advancement, and accomplishment. People with a promotion focus strive toward ideals, hopes, and aspirations. The promotion focused people likewise tend to be eager for goal attainment. In contrast, a prevention focus regulates security needs. People with a prevention focus are concerned with safety and with attending to their oughts, duties, and responsibilities. They tend to fulfill goals by remaining vigilant. Regulatory focus, then, has a pronounced impact on an individual's motives, goals, desires, decision-making, and behaviors (see Pham \& Higgins (2005) for a review).

Although regulatory focus has been widely investigated in relation to the consumer and social behavior during the past decade, considerable discussions remain about both its construct and measurements (Fellner, Holler, Kirchler, \& Schabmann, 2007; Haws, Dholakia, \& Bearden, 2010; Summerville \& Roese, 2008). Various approaches to the construct of regulatory focus have been proposed previously. Except for the promotion and prevention dichotomy, several researchers have proposed two dimensions regarding self-regulation, such as the subjective reference (i.e., desired versus undesired) and the regulatory action (i.e., approach versus avoidance) in self-regulatory theories by Carver and Scheier (1981) and Higgins (1997). Summerville and Roese (2008) had similar ideas and indicated two distinct conceptualizations of regulatory focus, namely the selfguide definition and the reference-point definition, both of which could further distinguish promotion and prevention focus from a different angle. The self-guide definition distinguishes promotion and prevention focus by the internal/personal (ideals) and the external/social (oughts) 
based standards, respectively. The reference-point definition represents promotion and prevention focus as regulation centering on a positive reference for a gain and a negative reference for a loss, respectively. These definitions and approaches implied multiple constructs rather than a single and unitary promotion or prevention construct.

Correspondingly, a number of measurements have been developed and utilized to determinate an individual's regulatory focus based on particular definitions. For example, the Regulatory Focus Questionnaire (RFQ; Higgins et al., 2001) and Self-Guide Strength Measure (SGSM; Higgins, Shah, \& Friedman, 1997) identify the regulatory focus by ideal versus ought guide definitions. However, the General Regulatory Focus Measure (GRFM; Lockwood, Jordan, \& Kunda, 2002) closely follows the gain versus loss reference-point definition. Another Behavioral Activation System/Behavioral Inhibition System scale (BIS/BAS; Carver \& White, 1994), which captures the reward approach and punishment avoidance, seems parallel with the reference-point definition. In fact, these measurements refer to different constructs and thus demonstrate a lack of convergence. Consequently, Summerville and Roese (2008) found that the RFQ and GRFM were uncorrelated. Haws et al. (2010), who worked on five regulatory focus scales, also found a low coherence among the measurements.

Considering the lack of consensus regarding the constructs and measurements of regulatory focus, a comprehensive scheme is needed for understanding and comparing the approaches to regulatory focus. Fortunately, most self-regulatory models lead to two fundamental dimensions: the objective reference (i.e., desired versus undesired) and the regulatory action (i.e., approach versus avoidance). These two dimensions are used to explore pertinent empirical issues in the current study. 


\section{Four Regulatory Forms}

Self-regulation is frequently conceptualized as a reference in which the individual's current state is compared to some projected state and how behavior is adjusted along the way to achieve the specific objective. Two dimensions regarding self-regulation have been noted: the valence of the reference (i.e., desired versus undesired) and the motivational movement (i.e., close to versus far from) in self-regulatory theories (Carver \& Scheier, 1981; Higgins, 1997). The desired reference is a goal that people desire to achieve or not to forgo such as ideals and oughts (Carver \& Scheier, 2011; Higgins, Roney, Crowe, \& Hymes, 1994). The opposite is the undesired reference, such as an evil identity (Erikson, 1963), bad me (Sullivan, 1953), or feared self (Markus \& Nurius, 1986). Later on, Carver and Scheier (1981) indicated two moving directions of motivational movement: approaching a desired reference and avoiding an undesired reference. In their model, approach and avoidance are in relation to a desired and undesired reference, respectively. Higgins (1997) argued that the approach and avoidance could be independent from the valence of the reference. Therefore, the desired versus undesired reference combined with the approach versus avoidance motivation to produce four different regulatory forms: "approaching desired references," "avoiding the absence of desired references," "approaching absence of undesired references," and "avoiding undesired references." To represent the regulatory forms simply, the current study indicates "approaching desired references" as goal pursuit; "avoiding the absence of desired references" as goal maintenance; and "avoiding undesired references" as negative escape. The "approaching the absence of undesired references" is termed active avoidance inspired by Carver and Scheier's (2001) feedback control model. Table 1 summarizes the four regulatory forms. 


\section{Research Purpose: Validating the Four Regulatory Forms}

The current study has three aims. The first is to determine which regulatory form is elaborated in the particular regulatory focus measurements and reveal the inconsistent conceptualizations of regulatory focus across measurements in Study 1. For example, the prevention subscale of the Regulatory Focus Questionnaire (RFQ; Higgins et al., 2001) may emphasize the goal maintenance (i.e., avoiding the absence of oughts) and the General Regulatory Focus Measure (GRFM; Lockwood et al., 2002) may focus on the negative escape (i.e., avoiding the failure). The items in RFQ are mainly not missing what we have to do; whereas the items in GRFM focus on not being unsuccessful. These two prevention subscales would represent goal maintenance and negative escape orientation respectively rather than a unitary construct of prevention focus.

The second aim is to explore the regulatory forms in the activations in Study 2. A number of approaches to activate promotion and prevention focus have been employed in previous studies (e.g., Higgins et al., 1994; Shah \& Higgins, 1997; Shah, Higgins, \& Friedman, 1998). Understanding the regulatory forms activated by the activations likewise provides future reseachers a reference for selecting proper activations in researching regulatory focus.

The third aim is to apply the regulatory forms to previous regulatory fit studies. Study 3 took a meta-analytic approach to understanding the effect of regulatory form matches on fit effects. This approach has the advantage, like all meta-analyses, of reducing the sampling errors, filedrawer effects, and enhancing reliability by examing issues across mutiple data sets from numerous researchers to provide an estimate of the construal-level effects (Schmidt \& Hunter, 2014). Although there is already attention to regulatory fit effects in terms of the different experimental conditions (e.g., by measurement or activation) and outcome variables (e.g., evaluation, behavior intention, or behavior; see Motyka et al., 2014), further examining the fit 
effect of the matches of regulatory form can contribute to explaining the heterogeneous results of previous regulatory fit studies on a theorical basis.

\section{Study 1: Exploring the Regulatory Forms in Regulatory Focus Measurements}

A number of measurements were developed to assess people's chronic differences in regulatory focus orientation. Based on the self-discrepancy theory (Higgins, Bond, Klein, \& Strauman, 1986; Higgins et al., 1994) and regulatory focus theory (Higgins, 1997), the regulatory forms in the six commonly employed measurements were investigated in this study: the Selves Questionnaire (Higgins et al., 1986), the Self-Guide Strength Measure (SGSM; Higgins et al., 1997), the Regulatory Focus Questionnaire (RFQ; Higgins et al., 2001), the General Regulatory Focus Measure (GRFM; Lockwood et al., 2002), the Behavioral Activation System / Behavioral Inhibition System scale (BIS/BAS; Carver \& White, 1994), and Composite Regulatory Focus Scale (CRFS; Haws et al., 2010).

By identifying regulatory forms in the regulatory focus measurements, this study firstly aims at revealing the source of heterogeneousness among these measurements. Haws et al. (2010) and Summerville and Roese (2008) provided an initial and insightful investigation of the relationship among regulatory focus measurements. First, high internal consistency of promotion and prevention subscales in each measurement was found (i.e., the Cronbach's $\alpha$ and the goodness-offit measures for the CFAs in Haws et al., 2010). The findings demonstrated that each promotion or prevention subscale successfully represents a single concept of regulatory focus in each measurement. Second, both Haws et al. (2010) and Summerville and Roese (2008) found high correlations among promotion subscales of regulatory focus measurements but less coherence among prevention subscales. The high correlations among promotion subscales aligned with our proposition that all these promotion subscales represent the same regulatory form of a goal pursuit 
orientation. The current study argued that the less coherence among prevention subscales was originated from the different regulatory forms of goal maintenance and negative escape accessed by these prevention subscales. The detailed statistics demonstrated in Haws et al. (2010) shed further light on this proposition. They consistently found that GRFM prevention subscale and BIS scale have a high positive correlation (i.e., $r=.36$ in their Study 1 and $r=.39$ with the replication sample); whereas, RFQ prevention subscale is uncorrelated with GRFM prevention subscale and BIS scale. Summerville and Roese (2008) provided parallel findings that the RFQ prevention subscale was actually negatively corrected with the GRFM prevention subscale. If, as expected in this study, GRFM prevention subscale and BIS scale access the regulatory form of negative escape, and RFQ prevention subscale measures the goal maintenance, two factors would be found when the items of the three prevention subscales are pooled together, and the same result patterns in Haws et al. (2010) and Summerville and Roese (2008) sould be reproduced in this study.

\section{Goal Pursuit}

Both self-discrepancy theory and regulatory focus theory indicated ideals as the maximum achievement which people may attain (e.g., Higgins, 1987; Rogers, 1961) and people tend to attain ideals, successes, or rewards by way of an approach (Higgins, 1997). This regulatory form is a goal pursuit. The promotion subscales of the Selves Questionnaire, the SGSM, RFQ, GRFM, and BAS scale represent such regulatory forms of goal pursuit.

The Selves Questionnaire assesses the degree of congruency between the actual-self and the ideal-self. When people value an ideal-self, they are motivated to reduce the discrepancy between their actual- and ideal-self. In other words, they approach the desired reference of an ideal-self. Similarly, the SGSM assesses people's emphasis on ideals by employing response latency as an indicator. People complete the tasks of eliciting desired attributes that they aspire toward, followed 
by a rating of ideals on a computer to record the response latency. Strong ideals, as expressed by fast responses, suggest important goals to which people approach.

RFQ is grounded in achievement motivation. The anticipatory reactions to new goals are derived from people's subjective history of success. People who have a long history of success in attaining hopes and accomplishments tend to move toward new goals by way of the same approach. For example, RFQ uses the item "I feel like I have made progress toward being successful in my life," to gauge the chronic promotion focus toward new goals by reasoning that a similar selfregulating goal pursuit will be involved. GRFM represents the promotion focused people as those who favor a way of approach to attain desired outcomes. For example, GRFM uses the item, "In general, I am focused on achieving positive outcomes in my life."

BAS scale was developed by Carver and White (1994) to indicate the behavioral activation system. BAS is a reward sensitivity scale that includes items pertaining to persistently pursuing desired outcomes, desiring new rewards, being willing to approach a potentially rewarding event, and positively responding to incidental or anticipated rewards. Previous scholars have employed BAS to determine a promotion focus. This study suggests the BAS scale is related to desired rewards and likewise associated to the regulatory form of goal pursuit.

CRFS composes the promotion items from the RFQ, GRFM, and BAS scales (Haws et al., 2010). The two items of RFQ are "When it comes to achieving things that are important to me, I find that I don't perform as well as I would ideally like to do" and "I feel like I have made progress toward being successful in my life." The two items from GRFM are "I frequently imagine how I will achieve my hopes and aspirations" and "I see myself as someone who is primarily striving to reach my 'ideal self' - to fulfill my hopes, wishes, and aspirations." One item "When I see an 
opportunity for something I like, I get excited right away" from the BAS scale is included in the promotion subscale of CRFS. All these items involve a goal pursuit orientation.

\section{Goal Maintenance}

A goal pursuit is not the only condition in which people often find themselves when moving toward the desired reference. Indeed, people also often maintain the desired states that they have already attained (Brodscholl, Kober, \& Higgins, 2007; Rothman, Baldwin, Hertel, \& Fuglestad, 2011). The oughts are the minimum performance which people must fulfill (Higgins, 1994). People tend to maintain the oughts by way of avoidance. In other words, they avoid missing the oughts (Higgins, 1997). This regulatory form is goal maintenance. The prevention subscale of the Selves Questionnaire, the SGSM, and RFQ are expected to measure the goal maintenance orientation.

The Selves Questionnaire assesses the degree of congruency between the actual-self and the ought-self to represent the prevention focus orientation. The SGSM employed the fast response for the oughts to indicate the prevention focused people's important self-regulation goal. Furthermore, RFQ argued that people who have a long history of success in fulfilling safety goals and responsibilities tend to move toward new goals by way of the same avoidance. For example, RFQ uses the item, "How often did you obey rules and regulations that were established by your parents," to represent the oughts maintenance which would be involved toward achieving those new goals via a prevention focus (Cesario, Grant, and Higgins 2004).

\section{Negative Escape}

When an undesired reference is set, people generally move themselves as far away from it as possible (Higgins, 1997) by way of an avoidance. This regulatory form is negative escape. The prevention subscale of GRFM and BIS scale represent this regulatory form. GRFM indicates that 
prevention focused people are used to moving themselves away from danger or threats by way of avoidance. For example, it employs the item, "I frequently think about how I can prevent failure in my life," to represent prevention focus. The BIS scale is a punishment sensitivity scale that comprises all items related to reactions to an anticipated punishment. BIS was employed to assess the prevention focus; the current study suggests BIS involves avoiding punishment, thereby fitting in the definition of negative escape in regulatory forms.

CRFS composes the prevention items from RFQ, GRFM, and BIS scales. Based on the surface meanings of each item, "Not being careful enough has gotten me into trouble at times," "I worry about making mistakes," and "I frequently think about how I can prevent failures in my life" involve avoiding negatives. However, the two items, "I usually obeyed rules and regulations that were established by my parents" and "I see myself as someone who is primarily striving to become the self I 'ought' to be-fulfill my duties, responsibilities and obligations" associate with oughts maintenance. Therefore, both negative escape and goal maintenance orientations would be accessed by CRFS.

\section{Active Avoidance}

Occasionally, people can avoid an undesired reference to which they are averse by way of an approach to seek another object or situation. The current study adopts the phrase active avoidance, designated in Carver and Scheier's feedback control model (1981), which entails the dynamic balance between the influences of avoiding the undesired reference by approaching another desired reference. The dual concept of avoiding an undesired reference by approaching another desired one may be hard to capture by the measurements. No existing measurement can access this regulatory form. 


\section{Summary of Scale Predictions}

As illustrated in Table 2, the six promotion subscales assess a goal pursuit orientation; however, the regulatory forms assessed by the prevention subscales differ. The Selves Questionnaire, SGSM, and RFQ's prevention subscales involve a goal maintenance orientation; whereas, GRFM's prevention subscale and BIS scale are related to a negative escape orientation. The prevention subscale of CRFS involves both goal maintenance and negative escape orientation. These expectations will be examined in Study 1 by a pooled survey of the above measurements; correlations and factor analyses are then used to reveal the similarity and difference among scales.

It was clear that the current study did not included all the regulatory focus scales. The selected ones were more frequently used in previous studies. Some scales were not popularin the following studies, such as Regulatory Focus Scale (Fellner et al., 2007). Some other measuerments were not considered because of the low reliability or discriminant validity, such as Regulatory Strength Measure (RSM; Shah, Higgins, and Friedman, 1998) which had a positive correlation of $r=.58$ for ideals and oughts, "making a distinction between individuals with a dominant promotion focus or prevention focus impossible (Fellner et al., 2007, p.113).”

\section{Method}

Survey I: participants, materials, and procedure. The first part of Study 1 was to examine whether all the promotion subscales represented the goal pursuit orientation solely and whether the prevention subscales should be split into goal maintenance and negative escape orientations. In order to keep the questionnaire in a reasonable length to prevent the fatigue effect, and to be corresponding with the findings of Haws et al. (2010) and Summerville and Roese (2008), two questionnaires was devised. One was a pool of RFQ and GRFM (25 items list in Appendix A), the other was a pool of RFQ and BIS/BAS scale (23 items list in Appendix B). Such division likewise 
contributed to the comparison of constructs accessed by RFQ (i.e., goal pursuit and goal maintenance) with those measured by GRFM and BIA/BAS scale (i.e., goal pursuit and negative escape). Two expectations followed. First, three constructs should be found, namely goal pursuit, goal maintenance, and negative escape, within each set of questionnaires which pooled RFQ and GRFM items or RFQ and BIS/BAS scale items together. Literally, RFQ's promotion subscale would highly correlate with GRFM's promotion subscale and BAS scale because they all access goal pursuit orientation. However, RFQ's prevention subscale was not expected to correlate with either GRFM's prevention subscale or BIS scale, because of the diverse goal maintenance and negative escape which are accessed by RFQ' prevention subscale and the other two prevention subscales, respectively.

Participants were invited to complete one of the two on-line questionnaires randomly. Eighty undergraduates in business school (52 females and 28 males) participated in this part of the study in exchange for a lottery for winning $€ 5$. They were randomly assigned to answer one of the two questionnaires. Half the participants filled out the RFQ and GRFM questionnaire, 14 males and 26 females, with an average age of $21.2(\mathrm{SD}=2.63)$. Among the other forty participants who completed the RFQ and BIS/BAS questionnaire, 14 were males and 26 were females with an average age of $21.9(\mathrm{SD}=2.53)$. The two subsamples were comparable in gender and age. All items within each questionnaire set were randomly arranged to eliminate the order effects.

Survey II: participants, materials, and procedure. To clearly demonstrate the constructs underlying prevention subscales, another questionnaire pooled all prevention items of RFQ, GRFM, and BIS scale was conducted. First, the same collection patterns in Haws et al. (2010) and Summerville and Roese (2008) will be replicated in this study. In other words, a positive correlation between GRFM and BIS prevention subscales is expected; however, the RFQ 
prevention subscle which represents goal maintenance would be uncorrelated with GRFM subscale and BIS scale. Second, two factors, namely goal maintenance and negative escape, account for above result patterns. Another sample of thirty-five undergraduates in business school (21 females and 14 males), with an average age of $21.1(\mathrm{SD}=2.18)$ completed the prevention items of $\mathrm{RFQ}$, GRFM, and BIS.

Survey III: participants, materials, and procedure. CRFS was employed in Survey III to replicate previous findings that promotion subscales represent single goal pursuit orientation, whereas the prevention subscales refer to diverse goal maintenance and negative avoidance orientation. CRFS composes ten items from the RFQ, GRFM, or BAS scales (Haws et al., 2010). All five promotion items involve a goal pursuit orientation. Based on the surface meanings of the prevention items, three items relate to negative avoidance and the other two items involve goal maintenance.

CRFS were conducted on two different samples. One sample which consisted of 64 MBA students (36 females and 28 males; age: $M=23.7, \mathrm{SD}=3.43$ ) of National Chengchi University; Another sample which consisted of 147 participants (60 females and 87 males; age: $M=22.69$, $\mathrm{SD}=2.53$ ) students who were recruited on the campus of Eindhoven University of Technology in the Netherlands. This European sample could enhance the external validity of the current study, and would be employed to examine the goal pursuit, goal maintenance, and negative escape orientations via a confirmation factor analysis (CFA).

Two other measurements, Selves Questionnaire and SGSM, were not in consideration at this questionnaire comparison stage. Although the Selves Questionnaire can be used with these rating scales, its outcomes are difficult to compare between respondents because the items of ideal- and ought-self are subjectively proposed by each person. The SGSM employs an indirect and implicit 
approach to assess respondents' ideal- and ought-self strengths through response latency. Therefore, the prediction is suspended for later study.

Survey I Results: The Relationships and Regulatory Forms in the Regulatory Focus

\section{Measurements}

Findings of inter-correlations. The results of the first survey had two folds: One was related to relationship and regulatory forms in RFQ and GRFM, and the other involved those in RFQ and BIS/BAS. As expected, the correlations between subscales of RFQ and GRFM indicated the significant positive correlation between both promotion subscales $(r=.64, p<.001)$; whereas, both prevention subscales were uncorrelated $(r=-.10, p=.53)$. Table 3 lists the means, standard deviations, reliabilities, and inter-correlations of the subscales of RFQ and GRFM. On the other hand, RFQ's promotion subscale was positively correlated with BAS $(r=.67, p<.001)$; whereas, the correlation between RFQ's prevention subscale and BIS was nonexistent $(r=-.07, p=.66)$. Table 4 lists the statistics of RFQ and BIS/BAS. This part of findings confirmed that the goal pursuit items in promotion subscales were convergent. However, less coherence was found among prevention subscales, which may due to different emphases of goal maintenance and negative escape. This argument was further examined by the coming factor analyses.

Findings of factor analyses. The exploratory factor analyses (EFA) were conducted to reveal the regulatory forms assessed by measurements on the two data sets. One set consisted the 11-item RFQ and 14-item GRFM; and, the other set consisted the 11-item RFQ and 12-item BIS/BAS. The principal component extraction and varimax rotation were employed to interpret the factor loadings. The number of components extracted was based on the Kaiser criterion (eigenvalues > 1) and the examination of a scree plot. Three components were extracted from the pooling RFQ and GRFM, and those of RFQ and BIS/BAS as well. 
When pooling RFQ and GRFM items together, the EFA indicated three components (see Appendix A). Most RFQ promotion items and all GRFM promotion items are loaded on the first component (eigenvalue: 4.99). Two of RFQ's promotion items, “Compared to most people, are you typically unable to get what you want out of life?" and "When it comes to achieving things that are important to me, I find that I don't perform as well as I ideally would like to do," were loaded on the second component along with GRFM's prevention items.

Most GRFM prevention items grouped into the second component (eigenvalue: 4.26) and revealed the meaning of "escape" through failure or negatives. However, two GRFM items, "I am anxious that I will fall short of my responsibilities and obligations" and "I see myself as someone who is primarily striving to become the self I ought to be-fulfill my duties, responsibilities, and obligations," may represent “ought maintenance" along with RFQ's prevention items (eigenvalue: 4.07). RFQ's item, “Did you get on your parents' nerves often when you were growing up?" showed cross-loadings on both negative escape and goal maintenance components.

Pooling items of RFQ and BIS/BAS together, the EFA results indicated three components again (see Appendix B). All RFQ's promotion items and most BAS items grouped into the first component (eigenvalue: 5.41), with the exception of the item "When good things happen to me, it affects me strongly." BIS items grouped into the second component (eigenvalue: 3.82), representing negative escape, except for the reverse item, "I have very few fears compared to my friends." RFQ's prevention items grouped into the third component (eigenvalue: 2.81), representing goal maintenance, with the exception of the item, "Not being careful enough has gotten me into trouble at times." 


\section{Survey II Results: The Diverse Regulatory Forms in the Prevention Subscales}

Descriptive statistics. The mean (and SD) of 5-item RFQ's prevention subscale, 7-item GRFM's prevention subscale, and 7-item BIS scale was 4.00 (1.18), 4.70 (0.79), and 5.15 (0.81), respectively. The Cronbach's alpha of these three prevention subscales were from .60 to .78 .

Findings of inter-correlations. A positive correlation was found between the GRFM prevention subscale and BIS $(r=.49, p<.001)$ as expected. The RFQ prevention subscale did not correlate with either the GRFM prevention subscale $(r=.12, p=.47)$ or BIS $(r=.12, p=.45)$.

Findings of factor analyses. Two factors were extracted from the prevention items of RFQ, GRFM, and BIS (see Appendix C). Most GRFM prevention and all BIS items were grouped into the first component (eigenvalue: 4.42). The oughts maintenance related items in GRFM, "I am anxious that I will fall short of my responsibilities and obligations" and "I see myself as someone who is primarily striving to become the self I 'ought' to be-fulfill my duties, responsibilities, and obligations" were grouped into the second component along with RFQ prevention items (eigenvalue: 3.78 ).

\section{Survey III Results: Regulatory Forms Accessed by CRFS}

Findings of the EFA and inter-correlations. An EFA was conducted on the first sample. Three factors were found in CRFS (see Appendix D). Five promotion items loaded on the first component (eigenvalue: 3.15$)$. The prevention items grouped into the other two components. Three prevention items loaded on the second component (eigenvalue: 1.99), which were, "Not being careful enough has gotten me into trouble at times (reversed score)," "I worry about making mistakes," and "I frequently think about how I can prevent failures in my life." These items involved avoiding mistakes and failures. Two prevention items grouped into the third component (eigenvalue: 1.47), which were, "I usually obeyed rules and regulations that were established by 
my parents," and "I see myself as someone who is primarily striving to become the self I 'ought' to be-fulfill my duties, responsibilities, and obligations." These two items were related to obeying the rules and maintaining the oughts.

The promotion items were averaged to represent the goal pursuit with a mean equal to 5.83 $(\mathrm{SD}=.75)$. The prevention items loaded on the second or the third component were averaged to be the negative escape $($ mean $=4.63, \mathrm{SD}=1.10)$ or goal maintenance $($ mean $=3.72, \mathrm{SD}=1.20)$ score, respectively. The goal pursuit score did not correlate with either the goal maintenance $(r=$ $-.06, p=.63)$ or the negative escape score $(r=-.22, p=.08)$. A slight positive correlation was found between goal maintenance and negative escape $(r=.32, p=.05)$. To explore the possible reason for this unexpected positive correlation, the relationships among prevention items were reviewed. The results indicated that the item "Not being careful enough has gotten me into trouble at times (reverse score)" (which is supposed to access negative escape orientation) positively corrected ( $r=.30, p=.03)$ with the item "I see myself as someone who is primarily striving to become the self I 'ought' to be-fulfill my duties, responsibilities, and obligations" (which is supposed to measure goal maintenance orientation); furthermore, the item "Not being careful enough has gotten me into trouble at times (reverse score)" was slightly correlated with the other goal maintenance item "I usually obeyed rules and regulations that were established by my parents" $(r=.27, p=.06)$. Excluding this suspended item and re-calculating the inter-correction, a nonsignificant correction was found between the goal maintenance and negative escape $(r=.16$, $p=.26)$. It implied that "Not being careful enough has gotten me into trouble at times" may lead someone to escape from failure, as well as to keep one's current status and goal.

Findings of the CFA. A CFA was conducted on 147 students to assess the factor structure. The results of this analysis were again consistent with three conceptualized goal pursuit, goal 
maintenance, and negative escape orientation. The model fit was indicated by the root mean square error of approximation (RMSEA), standardized root mean square residual (SRMR), normed fit index (NFI), and comparative fit index (CFI). The measurement model fit the three regulatory forms reasonably well. The goodness-of-fit measures of the goal pursuit (5 promotion items), goal maintenance (2 items marked with * in Appendix D), and negative escape (3 items marked with ** in Appendix D) model were: RMSEA $=.08$ and SRMR $=.06 ; \mathrm{NNFI}=.92$ and CFI $=.94$, which have reached the satisfactory model fit criteria indicated by Bentler (1990) and Marsh, Balla, and Hau (1996). The goal pursuit score did not correlate with either the goal maintenance $(r=.14)$ or the negative escape score $(r=-.08)$. The goal maintenance score did not correlate with the negative escape score $(r=-.01)$. These findings further supported the main argument that the coherence among promotion subscales and the diversion among prevention subscales.

\section{Discussion}

The results of the first part of Study 1 supported the claim that the promotion items of RFQ, GRFM, and BAS revealed a similar underlying construct, which represented the goal pursuit orientation. The correlational results indicated that the RFQ promotion subscale was positively correlated with the GRFM promotion subscale and the BAS. The current findings could offer a response to Summerville and Roese (2008) and Haws et al. (2010). In their Study 1, Summerville and Roese (2008) found that the correlations of promotion subscales of RFQ and GRFM was $r$ $=.39$, RFQ and BAS was $r=.32$, and GRFM and BAS was $r=.55$. Furthermore, Summerville and Roese, except for dividing the items of RFQ, GRFM, and BIS/BAS scale into "gain" and "loss" subsets, created the subset of non-gain and non-loss items. Their the gain items (i.e., goal pursuit) were highly coherence $(\alpha=.82)$, so they further proposed that promotion subscales of GRFM and BAS “may tap into the same underlying construct (p. 250)." Haws and his colleagues demonstrated 
parallel results of the correlations between RFQ, GRFM, and BAS/BIS subscales in two samples. They also found positive inter-correlations among these three promotion subscales. The RFQ promotion subscale was positively related with the GRFM promotion subscale $(r=.25$ and .27$)$ and the BAS ( $r=.21$ and .21$)$. The GRFM promotion subscale was also highly correlated with the $\operatorname{BAS}(r=.38$ and .51$)$.

In terms of prevention subscales, it is expected that RFQ prevention subscale indicated a different construct from the GRFM prevention subscale and the BIS. The results of the intercorrelations and EFA in the current study supported the postulate. According to the current results, the RFQ prevention subscale did not correlate with either the GRFM prevention subscale or the BIS. The inter-correlations among these three prevention subscales further indicated that the GRFM prevention subscale was highly correlated with BIS $(r=.58)$. These results were consistent with Haws et al. (2010) in which the RFQ prevention subscale did not correlate with the other two prevention subscales (GRFM: $r=-.14$ and -.18; BIS: $r=.20$ and .12 ); whereas, a positive correlation was found between the GRFM prevention subscale and the BIS ( $r=.36$ and .39$)$. Our finding pattern also synchronized with Summerville and Roese's (2008) results that GRFM prevention subscle was stongly related to BIS scale $(r=.54)$, whereas negatively corrected with RFQ prevention subscale ( $r=-.15)$. Conceptually, Summervill and Roese (2008, p. 250) argued that GRFM prevention subscale and BIS scale accessed the same "loss" construct which corresponded to our negative escape orientation. Meanwhile, the prevention subscales of RFQ and GRFM were negative corrected. This finding indicated that RFQ and GRFM prevention subscales should refer to different constructs in regualtory focus. We argued that the different constructs were goal maintenance and negative escape. 
In addition to the consistent pattern of inter-correlations with Haws et al. (2010) and Summerville and Roese (2008), the current study tried to explain the fact that these promotion subscales are homogenous, but prevention subscales are heterogeneous according to factor analyses. Three components were found from pooled items of the RFQ and GRFM: one component represented the promotion focus and the other two components represented RFQ and GRFM prevention focus. Similar patterns were found in the combined survey of the RFQ and BIS/BAS. The diversity among prevention subscales was enhanced. Then, the EFA result of only prevention items illustrated that most of the GRFM prevention subscale and BIS shared the same construct and RFQ represented a different construct. The EFA and CFA results found in CRFS doubly supported that the promotion items indicated one construct (i.e., goal pursuit) and the prevention items indicated two different constructs (i.e., goal maintenance and negative escape). Both results of the inter-correlations and factor analyses strongly supported our argument that these three promotion subscales reasonably assess the same regulatory form of goal pursuit; whereas the prevention focus measurements are heterogeneous because of diverse goal maintenance and negative escape.

\section{Study 2: Exploring the Regulatory Forms in Regulatory Focus Activations}

Study 2 aims at regulatory focus activations to examine the categorization effectiveness of goal pursuit, goal maintenance, negative escape, and active avoidance. Promotion and prevention focus can also be temporarily activated. A number of approaches for activating regulatory focus have been employed in previous studies. Most activations could be easily mapped on the objective reference and regulatory action framework. For example, Cesario, Grant, and Higgins (2004) and Brodscholl et al. (2007) framed regulatory focus by attaining or maintaining the rewards or goals (i.e., goal pursuit or goal maintenance). Idson, Liberman, and Higgins (2004) direted individuals' 
focus on receiving a discount (i.e., goal pursuit) versus avoiding a penalty (i.e., negative escape). Plessner, Unkelbach, Memmert, Baltes, and Kolb (2009) directed players to score hits or miss shots in the penalty in a shooting task to be promotion and prevention focus, respectively. In this case, scoring the shoots should be a goal pursuit, whereas avoiding missing the shoots should be a goal maintenance. Meanwhile, reulatory focus can be also triggered by priming ideals or oughts (Self-Guide Priming, SGP; Higgins et al., 1994), by completing promotion- or prevention-words (Words Completion Task (WCT); Lee \& Aaker, 2004), or by completing a maze that highlights nurturance versus security concerns (Maze Priming Technique (MPT); Friedman \& Förster, 2001). The later aforementioned three activation methods are more complicated to map in the objective reference and regulatory action framework. This study would not exhasivly examine all the regulatory activations but focus on examining these three complicated ones.

The SGP (Higgins et al., 1994) was developed to draw focus on ideal- or ought-self. The ideal priming instructions state, "Describe how your hopes and aspirations are different now from when you were growing up." The goal pursuit is expected to be activated by the ideal priming. In the ought priming instructions, the phrase "hopes and aspirations" is replaced with "duties and obligations." The goal maintenance is expected to be involved in the ought priming. Another method, WCT, used to prime a particular regulatory focus which follows the self-guide definition is by asking people to complete promotion- (e.g., e_g_r [eager], h_pe [hope]) or prevention- (e.g., d_ty [duty], s_fe [safe]) words. Completing specific words such as "hope" and "aspiration" can prime people's ideals and foster their focus on goal pursuit. In contrast, completing words such as "duty" and "responsibility" can prime people's oughts and lead their focus toward goal maintenance. Furthermore, prevention-words regarding risks can be used to induce a focus on 
“escape," because "high risk made negative outcomes more salient" (Lee \& Aaker, 2004, p. 212) and people are motivated to escape negative outcomes.

Regulatory focus theory (Higgins, 1997) asserts that promotion focused people concern themselves with attaining nurturance needs and prevention focused people emphasize fulfilling security needs. The MPT was developed (Friedman \& Förster, 2001) based on such need of nurturance attainment and security fulfillment. In the nurturance-attainment task, participants pretend to be the mouse inside a maze and attempt to get the cheese at the end of the maze. It is a "pursuit" task for approaching desired outcomes, thus forms the goal pursuit. On the other hand, in the security-fulfillment task, participants pretend to be a mouse to reach a safe site at the end of a maze to avoid being captured by an owl. Respondents experience a threat and try to find a safe location in the maze. In other words, participants not only escape from the undesired object (i.e., the owl) but also approach a desired reference (i.e., a safe end) in completing the securityfulfillment task. Consequently, an active avoidance is expected when participants complete the security fulfillment task of MPT.

\section{Summary and Predictions}

The above predictions regarding the particular regulatory forms induced by the regulatory focus activations were examined in Study 2, with the RFQ, GRFM, and BIS/BAS measurements whose regulatory forms have been assessed in Study 1 as the indicators. Table 5 lists the predictions of these three regulatory focus activations.

\section{Method}

Study 2 examined which regulatory form was embeded in regulatory focus activations, including ideal self-guide priming, ought self-guide priming, promotion-words completion, prevention-words completion, nurturance-attainment, and security-fulfillment. 
Participants, materials, and procedure. Two hundred and ten (142 females and 68 males) undergraduate students in a business school, with an average age of $20.7(S D=3.07)$, participated in the experiment in exchange for a small gift. They were randomly assigned into six conditions: ideal self-guide priming $(N=34)$, ought self-guide priming $(N=35)$, promotion-words completion $(N=34)$, prevention-words completion $(N=34)$, nurturance-attainment $(N=36)$, and securityfulfillment $(N=37)$ tasks.

The standard procedures for the SGP (Freitas and Higgins, 2002) and MPT (Friedman and Förster, 2001) were followed. The promotion-words used in the WCT were: "eager," "dream," "hope," "success," "seek," and "ideal"; whereas, the prevention-words were: "careful," "necessary," "duty," "safe," "obligation," and "risk." At the end of the activation, the responses of 11-item RFQ, 14-item GRFM, and 12-item BIS/BAS on five-point scales were collected to indicate goal pursuit, goal maintenance, negative escape, and active avoidance orientation.

Indicators for regulatory forms. Employing the findings in the first part of Study 1, RFQ's promotion items, which consistently had higher than .50 loading value on the first factor, were used to represent goal pursuit (2 items). With the same criteria, six of GRFM's promotion items and three BAS items were also selected. These 11 items were averaged to form the goal pursuit indicator (the items marked with \# in Appendix A and B). The goal maintenance and negative escape indicators were based on the results in the second part of Study 1. Prevention items by the same criteria (factor loading $>.50$ ) were averaged to form the indicators of goal maintenance (six items marked with * in Appendix C; the item "I often think about the person I am afraid I might become in the future," which was crossly loaded on two dimensions, was excluded) and negative escape (eight items marked with ** in Appendix C). The active avoidance involves the dual influence of discrepancy-amplifying from a negative reference by approaching another goal. This 
concept is hard to capture by any existing measurement and therefore remains untreated in the analyses.

\section{Results}

Self-guide priming (SGP). The planned contrasting statistics indicated that participants receiving ideal priming had higher promotion scores than those receiving ought priming (RFQ: $M$ $=3.71$ versus $3.33, t(67)=2.56$, Cohen's $d=.62, p=.01$; GRFM: $M=4.08$ versus $3.84, t(67)=$ $2.30, d=.55, p=.03 ;$ BAS: $M=4.46$ versus $4.22, t(67)=1.91, d=.46, p=.06)$. In contrast, participants focused on oughts had a higher RFQ prevention score, than those who focused on ideals (RFQ: $M=3.45$ versus $2.99, t(67)=2.51, d=.60, p=.02$ ). Besides, oughts and ideals focused participants had similar GRFM prevention and BIS scores (GRFM: $M=3.18$ versus 3.12, $t(67)=.38, d=.07, p=.71$; BIS: $M=3.75$ versus $3.61, t(67)=1.04, d=.25, p=.30)$.

In terms of regulatory form indicators, the planned contrasting statistics indicated that participants receiving ideal priming had a higher goal pursuit score than those receiving ought priming $(M=4.00$ versus $3.75, t(67)=2.90, d=.70, p=.01)$. In contrast, participants focused on oughts had a higher goal maintenance score than those who focused on ideals $(M=3.69$ versus $3.30, t(67)=2.54, d=.61, p=.01)$. However, oughts-focused participants and ideals-focused participants had similar negative escape scores $(M=3.60$ versus $3.46, t(67)=1.11, d=.27, p$ $=.27)$. The results were summarized in Table 6 .

Word completion task (WCT). The results showed that participants completing promotionwords had higher promotion scores than those who completed the prevention-words (RFQ: $M=$ 3.53 versus $3.24, t(66)=2.31, d=.56, p=.02$; GRFM: $M=4.13$ versus $3.89, t(66)=2.13, d$ $=.52, p=.04$; BAS: $M=4.45$ versus $4.35, t(66)=.94, d=.23, p=.35)$. In contrast, participants completing the prevention-words had slightly higher prevention scores in RFQ, GRFM, and BIS 
than those who completed the promotion-words (RFQ: $M=3.19$ versus $2.88, t(66)=1.75, d=.42$, $p=.09$; GRFM: $M=3.41$ versus $3.11, t(66)=2.47, d=.60, p=.02$; BIS: $M=3.71$ versus $3.67, t$ $(66)=.32, d=.08, p=.75)$.

In terms of the indicators of goal pursuit, goal maintenance, and negative escape, participants completing promotion-words had a higher goal pursuit score than those who completed the promotion-words $(M=4.00$ versus $3.78, t(66)=2.52, d=.61, p=.01)$. A higher average goal maintenance was found when comparing participants completing prevention- and promotionwords $(M=3.53$ versus $3.22, t(66)=2.17, d=.53, p=.03)$. The average negative escape scores were similar between promotion-words and prevention-words completion groups ( $M=3.65$ versus $3.49, t(66)=1.37, d=.33, p=.18)$. These findings supported that completing promotion- or prevention-words could activate goal pursuit or goal maintenance orientation, respectively; but not negative escape. The findings were summarized in Table 5.

Maze priming technique (MPT). The results of promotion scores for participants guiding a mouse for cheese and directing the mouse toward a safe site to escape from the owl were similar (RFQ: $M=3.25$ versus $3.13, t(71)=1.49, d=.35, p=.14$; GRFM: $M=3.38$ versus $3.39, t(71)$ $=.12, d=.03, p=.91$; BAS: $M=4.33$ versus $4.36, t(71)=.23, d=.05, p=.82)$. In contrast, participants running from the owl had higher BIS scores than those seeking cheese (BIS: $M=3.79$ versus $3.55, t(71)=2.85, d=.67, p=.01)$. However, participants who completed the nurturanceattainment and security-fulfillment task had similar RFQ and GRFM prevention scores (RFQ: $M$ $=2.68$ versus $2.79, t(71)=1.40, d=.33, p=.17$ GRFM: $M=3.31$ versus $3.10, t(71)=1.55, d$ $=.36, p=.13$ ). The regulatory form indicators provided further insight for such incongruent results found in the prevention scores. 
Participants guiding mice for cheese had a similar goal pursuit score and goal maintenance score to those who directed the mouse running from the owl. The corresponding indicators had no significant difference (goal pursuit: $M=3.61$ versus $3.53, t(71)=.93, d=.22, p=.36$; goal maintenance: $M=3.05$ versus $3.05, t(71)=.03, d=.01, p=.98)$. However, participants running from the owl had higher escape scores than those seeking cheese $(M=3.76$ versus $3.55, t(71)=$ $2.65, d=.62, p=.01)$. Table 6 summarized the findings.

\section{Discussion}

In experimental studies, regulatory activations have been widely used to induce participants' regulatory focus. Study 2 demonstrated that the specific regulatory focus activations could induce a corresponding orientation of regulatory form. A major finding is that SGP and WCT can activate goal pursuit and goal maintenance orientations. Listing ideals and completing words regarding hope and aspirations can generate higher goal pursuit orientations than listing oughts and completing words involving duty and obligation. Listing or completing oughts related words can induce a higher goal maintenance orientation than listing or completing ideals related words.

The orientations activated by the MPT were more complex than SGP and WCT. Participants who guided the mouse to attain the cheese in the nurturance-attainment task revealed a high goal pursuit orientation, which is similar to the ideal self-guide priming and promotion-words completion task. More importantly, running away from an owl (which is equivalent to seeking a safe place) had as high a goal pursuit score as searching for cheese, but with a higher negative escape score than searching for cheese. The findings suggest that completing the securityfulfillment task may lead participants to engage in a dual process of active avoidance which refers

to approaching another desired end to avoid the current threat: namely, the activated prevention 
focus carries different regulatory forms between MPT versus SGP and WCT, which may also contribute to the heterogeneous results in previous regulatory fit studies.

Study 2 demonstrated that different regulatory forms were activated by particular regulatory focus activations. The results were supported by all the measurements which were discussed and distinguished in Study 1, and further enhanced by the regulatory form indicators based on the results of Study 1 . The consistent patterns of Study 1 and Study 2 highlight the need for subdividing regulatory focus into goal pursuit, goal maintenance, negative escape, and active avoidance orientation. Through these efforts, Study 3 aimed to bring greater clarity to the key aspects of regulatory focus and a deeper knowledge of the extent to which these measures and activations differ and overlap.

\section{Study 3: The Impacts of Regulatory Form Matches on Regulatory Fit Effects}

The ultimate purpose of this study is to examine how the matches of regulatory form impact regulatory fit effect. Regulatory fit occurs when people use strategies and engage in activities that are consistent with their goal orientation. As a result, people process information more fluently (Cesario et al., 2004; Lee \& Aaker, 2004), favor the present targets (Avnet, Laufer, \& Higgins, 2013; Higgins, 2006; Higgins, Idson, Freitas, Spiegel, \& Molden, 2003), and enhance the performance accuracy in completing cognitive tasks (de Lange \& van Knippenberg, 2009) when they experience regulatory fit rather than unfit. Study 3 proposed that the matches of regulatory forms could accurately predict the regulatory fit effects and explained the heterogeneous results of previous studies (e.g., a review see Motyka et al., 2014).

\section{Matches of Regulatory Form}

Studies of regulatory fit usually involve two steps. First, participants' promotion or prevention focus is identified by a measurement or activation; second, participants receive a 
message or complete a task, which either sustains or hampers such promotion or prevention focus and thus they experience a fit or unfit experience, respectively. Therefore, applying the regulatory forms on the first and second steps reported in previous research can identify the matching degree of the methods used in these regulatory fit studies.

For example, if researchers took the SGSM to assess participants' regulatory focus, it was expected that participants in the promotion focus group had a strong goal pursuit orientation and people in the prevention focus group had a strong goal maintenance orientation. Next, taking Wang and Lee's (2006) manipulation as our example for the second step, participants received information about a product's features either as a "pursuit" of a desired reference, such as breath freshening, teeth whitening, or tooth enamel strengthening or by an "escape" from an undesired reference, such as avoiding cavities or gingivitis. The promotion focused participants would experience fit because the message of attaining healthy teeth sustained their goal pursuit orientation; this combination was both a regulatory focus fit and a regulatory form fit. However, the prevention focused participant would not experience a perfect fit, with respect to the matches of regulatory form, because the cavity avoidance messages disrupted their goal maintenance orientation. This combination was identified as a fit according to regulatory focus, but not a fit regarding regulatory form. It implied that in this example, the fit effect would be stronger in the promotion than the prevention focus group according to the regulatory form categorization. However, the fit effect of the promotion and prevention group in the above example was expected to be equal according to the promotion and prevention focus fit.

In some regulatory fit studies, the method might partially sustain participant's regulatory form orientation. Taking Cesario et al. (2004) for example, prevention focused participants were selected by RFQ and they had high goal maintenance orientations. Participants then received an 
appeal for an after-school program: "The primary reason for supporting this program is because it will secure children's education and prevent more children from failing" (Cesario et al., 2004). The fit effects are likewise expected while participants received a mixed message. Particularly, in above example, the phrase, "secure education," sustained participants' goal maintenance orientation but the phrase "avoiding failures" did not. The perfect fit was not expected regarding matches of regulatory form, but a certain level of fit experience could happen in such case.

In the current study, we used the term "match" simply to distinguish the sustaining of regulatory forms from the regulatory fit regarding the sustaining of promotion and prevention focus. The three match levels of regulatory form in the current study were: a (good) match, a partial match, and a mismatch. We may picture the regulatory forms accessed by the measurement or activation as a matrix with four cells (i.e., goal pursuit, goal maintenance, negative escape, and active avoidance) and those manipulated by the following fit task as the other matrix. The two matrixes may perfectly overlap in terms of the four cells, namely above mentioned "match" (in mathematic terminology, the union of the two matrixes is equal to the intersection of the two). The four cells of the two matrixes may totally miss each other, called "mismatch" (i.e., the intersection of the two matrixes is null). If the two matrixes overlap on some but not exclusive cells (i.e., the union of the two matrixes is larger than the intersection of the two, and the intersection of the two is not null), it is a "partial match."

If regulatory forms are critical in self-regulation systems, the matches of regulatory form should generate the strongest fit effect. More importantly, the mismatch of regulatory form would produce the weakest fit effect, though the studies were manipulated as promotion or prevention fit. Consequently, the present study could argue that the discrimination of regulatory forms from 
regulatory focus is necessary for the understanding of heterogeneous regulatory fit effects (see Motyka et al., 2014).

\section{Method}

The meta-analysis was conducted in the following stages. First, the literature was located. Then, the regulatory forms in the manipulations were identified and coded; the outcome variables were likewise classified. Finally, the meta-analyses were conducted on the archival data and the sample-weighted $r$ was calculated to represent effect sizes. The group contrasts were tested using between-class goodness-of-fit $Q_{b}$ statistics.

Literature search. To locate sufficient studies, the meta-analyses were performed using data from 1998 to 2014, going back to when Förster, Higgins, and Idson first demonstrated regulatory fit as a "goal looms larger" effect. Literature in regulatory fit along with experimental studies published in peer-reviewed academic journals was selected from the online databases PsycINFO, PsycARTICLES, and ABI/INFORM Complete. The titles and abstracts of these articles were reviewed and those that did not meet the inclusion criteria were eliminated from further review. In addition, references listed in Motyka and his colleagues' meta-study of regulatory fit (Motyka et al., 2014) were included. Based on this step, 169 articles were considered.

The data selection. After an initial pool of potential articles had been collected, empirical studies with non-clinical samples with ages above twelve years old were selected for the following meta-analysis to examine regulatory form matches and whether they met four criteria.

1. A complete regulatory fit manipulation requires identification of participants' regulatory orientation and then leads participants to complete the task by methods which sustain or disrupt previous regulatory orientations. The studies which divided participants into groups without a discrimination of regulatory orientation were excluded. Furthermore, since we 
focused on goal-directed self-regulation, the few papers that examined global and local focuses were excluded (e.g., Förster \& Higgins, 2005).

2. The valid studies had to include appropriate statistics that could be used to calculate the contrast effects under specific regulatory orientations. The articles that only reported the interaction statistics of regulatory orientations with a moderator (e.g., Hendrix \& Hirt, 2009; Plessner et al., 2009; Sassenberg, Jonas, Shah, \& Brazy, 2007) or only reported fit versus unfit effects (e.g., Jin, 2010; Koenig, Cesario, Molden, Kosloff, \& Higgins, 2009; Memmert, Unkelbach, \& Ganns, 2010; Vaughn, Hesse, Petkova, \& Trudeau, 2009; Vaughn, Malik, Schwartz, Petkova, \& Trudeau, 2006) were excluded.

3. The sufficient statistics for calculating regulatory fit effect had to be reported (such as $t$ and $F$; or individual group means and standard deviations) in the articles. According to Rosenthal's (1991) recommendations, for the studies which merely indicated that the results were not significant, we assigned the effects an $r$ value equal to zero, which yielded conservative estimates of the effect.

The application of these criteria resulted in 93 remaining articles, containing 190 experiments. The list of articles used in meta-analysis is available upon request. One experiment commonly had two regulatory groups (i.e., promotion versus prevention-focus). These two groups were taken as independent samples. The corresponding regulatory form was identified in the promotion and prevention group separately. Some researchers used more than one set of samples in the experiments. Each sample was treated as an independent sample. Furthermore, researchers usually employed more than one dependent variable to demonstrate the regulatory fit effect. All dependent outcomes contributed to the data points. Finally, the 190 experiments generated 627 separate data points for the meta-analysis. 
Coding the regulatory forms. To investigate the impact of the regulatory form matches on regulatory fit effects, the goal pursuit, goal maintenance, negative escape, and active avoidance should be coded in advance. The first author and a doctoral researcher who was blind to the research hypothesis coded the regulatory forms of the manipulations in the selected articles independently. Regulatory forms in measurements and activations of the first step were mainly coded as suggested in Study 1 and 2 (see the list in Table 3 and 5). Beyond the mentioned methods, regulatory forms of other measurements or activations were coded by the desired or undesired reference and approach or avoidance action reported in the articles. Similarly, the regulatory forms embedded in messages or tasks in the second step were also coded. The inter-coder agreements were acceptable on the coding of measurements or activations in both steps (both Cohen's $K$ 's $>$.90). Remaining disagreements were resolved through discussion (Szymanski \& Henard, 2001).

Statistically, regulatory fit effects are represented as an outcomes comparison between a condition in which participants' regulatory focus is sustained (i.e., a fit condition) and another condition in which their regulatory focus is disrupted (i.e., an unfit condition). The regulatory forms in the fit and the unfit condition were coded independently.

Categorizing outcome variables. Previous regulatory fit studies demonstrated the effect via various outcome variables. To test the extension of the regulatory form matches, the outcome variables were classified into five categories: (1) processing fluency and right feeling (e.g., "ease of processing" and "fluency of perceptual identification" in Lee and Aaker (2004)), (2) attitude evaluation (e.g., "brand attitude" in Malaviya and Sternthal (2009)), (3) behavioral intention (e.g., "intention to eat more fruits and vegetables" in Cesario and the colleagues' (2004)), (4) behavior (e.g., "whether participants did or did not choose to play Shoot-the-Moon game again" in Higgins, Cesario, Hagiwara, Spiegel, and Pittman (2010)), and (5) cognitive performance (e.g., "stimulus 
identification sensitivity" in Glass, Maddox, and Markman (2011)). The first four outcome variables represented different stages of information processing. Processing fluency (Aaker and Lee, 2006; Avnet and Higgins, 2006; Cesario et al., 2004; Christopher J., Higgins, and Lindsay, 2003; Lee and Aaker, 2004) leads to attitudinal and behavioral consequences of the fit experience (Higgins, 2005; Higgins et al., 2003). Furthermore, behavioral expressions could be performances in cognitive tasks (e.g., task accuracy in Chalabaev, Major, Sarrazin, \& Cury, 2012 and McAuley et al., 2012) whose nature is quite unique.

Meta-analysis procedures. Standard formulas (Borenstein, Hedges, Higgins, \& Rothstein, 2009; Hedges \& Olkin, 1985) were employed to perform analyses based on the sample sizes, means, SDs, $t$ values, and $F$ ratios reported in articles. Because the manipulations were not identical in regulatory fit studies, the random-effects model was employed to include the errors beyond the sampling and estimate the mean of the regulatory fit effects. The sample-weighted $r$ was calculated to represent effect sizes (Borenstein et al., 2009). A larger effect size indicated that regulatory form fit resulted in more positive outcomes. Furthermore, the significant within-class goodness-of-fit $I^{2}$ statistic represented heterogeneity. The group contrasts were tested using between-class goodness-of-fit $Q_{b}$ statistics (Hedges \& Olkin, 1985).

Many regulatory fit studies reported more than one relevant outcome in a single experiment; however, using more than one effect size per sample violated the independence assumptions in the meta-analysis (Rosenthal, 1994). Therefore, when more than one outcome was reported from an experiment, the effect sizes were averaged into a single value to ensure each experiment contributed only one effect size (Borenstein et al., 2009). Publication bias was represented as a funnel plot and tested using Rosenthal's fail-safe $N$ (1979), which is a statistic that can be 
employed to estimate the number of unpublished null effect studies that must exist to reduce the effects to a significant level of $p=.05$.

\section{Results}

The promotion/prevention fit effects. The data set included a total of 368 independent effect sizes $(N=24,542)$ from regulatory fit studies. The sample-weighted mean effect size $r$ was attained according to a random model; the file drawer $N$, and $I^{2}$ were reported in Table 7 . The overall main regulatory fit effect was $r=.30, p<.001$, file drawer $N=226,652$. The effect sizes were from $r$ $=.28$ to $r=.33$. The effects on the particular outcome categories were: processing fluency $(r=.31$, $p<.001)$, attitude $(r=.31, p<.001)$, behavioral intention $(r=.29, p<.001)$, behavior $(r=.28, p$ $<.001)$, and cognitive performance $(r=.33, p<.001)$.

Fit effects generated by the matches of regulatory form. According to the proposed levels of regulatory form matches, two-thirds of studies demonstrated a match in the fit condition and mismatch in the unfit condition $(k=199)$. One-third of studies incidentally created a partial match or even a mismatch in the fit condition ( $k=29$ and $k=80$, respectively), and mismatch in the unfit condition. Few studies manipulated the match or partial match of regulatory forms in both fit and unfit conditions ( $k=5$ and $k=2$, respectively). These effect sizes (i.e., outcome differences) were not further discussed due to the small sample size.

The overall main effect generated by the matches of regulatory form was $r=.36, p<.001$, file drawer $N=106,382$. The positive mean effect size $r$ indicated that the matches of regulatory form results in positive effects on the dependent variable. As expected, comparing with the fit effects (overall main effect: $r=.30$; range: $r=.28-.33$; Table 8 ), the matches of regulatory form indicated a stronger effect (overall main effect: $r=.36$; range: $r=.34-.41$ ), $Q_{b}=11.08, p<.001$. The effects on the specific outcome categories were: processing fluency $(r=.39, p<.001)$, attitude 
$(r=.35, p<.001)$, behavioral intention $(r=.37, p<.001)$, behavior $(r=.34, p<.001)$, and cognitive performance $(r=.41, p<.001)$. Table 8 exhibits the statistics.

Match levels of regulatory form. The fit effects were along with the match levels of regulatory form. As shown in Table 9, the fit effects accompanied the match levels of regulatory

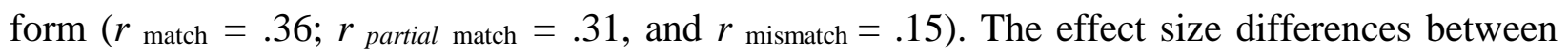
certain match levels were obvious $\left(r_{\text {match }}=.36\right.$ versus $r_{\text {partial match }}=.31, Q_{b}=6.25, p=.04 ; r_{\text {match }}$ $=.36$ versus $r$ mismatch $=.15, Q_{b}=37.00, p<.001 ; r_{\text {partial } \text { match }}=.31$ versus $r_{\text {mismatch }}=.15, Q_{b}=$ $10.78, p<.001)$.

\section{Discussion}

Study 3 employed the regulatory forms to examine the effects of regulatory fit studies. In general, most regulatory fit studies $(85.6 \%)$ could be reorganized by the reference valence (i.e., desired versus undesired) and by motivational movement (i.e., approach versus avoidance) frameworks. The regulatory form framework of goal pursuit, goal maintenance, negative escape, and active avoidance could be applied to virtually all the regulatory fit studies.

The meta-analysis results lend credence to the proposition that the match levels of regulatory form impact the regulatory fit experience. If the matches of regulatory form were sustained, the results demonstrated the consistent and strong fit effects. Furthermore, the regulatory forms could account for the heterogeneous effects in previous regulatory fit studies. In comparison to promotion/prevention fit effects $(r=.30)$, sustaining participants' regulatory form orientation could generate a stronger impact on outcome variables $(r=.36)$. The effect difference may lie in the weak effects generated in one-third of the regulatory fit studies in which the participants' regulatory form orientations were mismatched or partially matched. 
Study 3 further confirms the results from Study 1 and 2 regarding certain regulatory forms assessed by the measurements and activations. Taking the dependent outcomes in previous regulatory fit studies as the criteria, the identified regulatory forms successfully predicted the outcome effects. Although Study 3 has yielded findings that have both theoretical and practical implication, it was not without flaws. Without the sufficient data (partial matched: $k=2$; mismatched: $k=4$ ), Study 3 could not provide solid support for whether sustaining active avoidance orientation produces strong regulatory fit effect. Further research is needed.

\section{General Discussions}

\section{The Benefits of Applying Regulatory Forms}

The concept of regulatory focus has been influential in consumer research and applied psychology. As regulatory focus studies continue to grow, diverse regulatory focus measurements and activations emerged; however, the essence of these measurements and activations has not been fully investigated or evaluated. Therefore, further research is needed (see Haws et al., 2010). The current study employed the four regulatory forms noted by Higgins (1997) to illuminate the diverse representations in these methods. To bring the paper to an end, the regulatory forms could theoretically explain the heterogeneousness among regulatory measurements and activations; moreover, the regulatory forms could benefit the manipulation of regulatory fit.

Different regulatory forms involved in the measurements and activations. Study 1 and 2 consistently found that methods regarding prevention focus could be divided into goal maintenance and negative escape orientations. Self-regulation regarding the oughts was related to the goal maintenance orientation (i.e., a prevention-subscale in GRFM and oughts self-guide priming), which represented avoidance the absence of desired references (the oughts). The negative escape was represented as avoidance of a threat or failure (i.e., a prevention-subscale in 
GRFM and BIS). On the other hand, the promotion focus was conceptually related to the goal pursuit and active avoidance orientation. The goal pursuit orientation is consistently found with respect to the promotion focus in previous measurements and activations. However, the active avoidance orientation is complex and hard to be represented by any existing methods. Further research is needed for understanding active avoidance orientation.

Regulatory fit effect by matching regulatory forms. Study 3 included regulatory fit studies using various methods to identify regulatory orientation in the past 15 years. The findings demonstrated that the tasks used in previous studies which sustained regulatory form orientation exerted significant fit effects; furthermore, the fit effect sizes accompanied the degree of regulatory form matches. The fit effects of partial match and mismatch conditions, which was believed to be equal according to the promotion and prevention focus fit in previous studies, were not as good as the match conditions based on our regulatory form categorization.

With regard to regulatory forms, strong and coherent fit effects can be manipulated. To practice the matches of regulatory forms in manipulating regulatory fit, for example, participants with goal maintenance orientations could successfully experience fit when they are engaged in tasks such as avoiding missing desired objectives rather than escaping from failures or bad outcomes.

One additional analysis was conducted to further illustrate this suggestion directly. A data set was selected, including studies that identified regulatory orientation as an ought self-guide (i.e., the prevention subscale of a Selves Questionnaire, a SGSM, RFQ, and Ought Self-Guide Priming), to conduct a meta-analysis. The goal maintenance orientation was expected in these studies. A strong fit effect was exerted (i.e., $r=.42$ ) when the studies directed participants to focus on maintaining positives, such as using "strategies you could use to stop you from realizing your duty 
or obligation" (e.g., Vaughn et al. 2009), providing framing to maintain the rewards or alternatives they already have (e.g., Brodscholl et al., 2007; Cesario, Grant, \& Higgins, 2004), or emphasizing a reservation price in negotiations (e.g., Appelt et al. 2009). However, a relatively weak fit effect was found (i.e., $r=.14$ ) among the studies which manipulated tasks to sustain a negative escape orientation, such as avoiding bad health (Wang et al. 2011), negative outcomes (Reber, Lima, and Fosse 2007), failure-avoidance scenarios (Lee, Aaker, and Gardner 2000), or eliminating harmful elements (Freitas and Higgins 2002). These results further highlight that if researchers operate regulatory fit in a manner consistent with the regulatory form orientation, the regulatory fit effects should be more apparent than what were reported in the literature.

\section{Suggestions to Selecting Regulatory Focus Measurements}

Although the major purpose of the current study was to illustrate the importance of "match" in regulatory fit studies in terms of the two by two regulatory forms, our Study 1 also provided insight on measurement selection for future regulatory focus studies. First, researchers are recommended to consider their research purpose clearly. If researchers intend to simply dichotomize promotion focus as "ideal self-guide and approaching the gain" and prevention focus as "ought self-guild and avoiding the loss," the promotion part of most scales is applicable, but the prevention subscale should be carefully selected. When the researchers define prevention as "goal maintenance" through ought self-guide, then RFQ, Selves Questionnaire, and SGSM are recommended; otherwise if researchers consider prevention as a "negative escape" (i.e., avoiding the loss), GRFM and BIS should fit better.

As we found in Study 1, the existing promotion subscales all accessed one construct, namely goal pursuit, which was consistent with Summerville and Roese's (2008) "gain" factor (Cronbach's $\alpha$ of gain $=.82$ in their Study 2 ). The relatively low consistency within Summerville 
and Roese's "non-gain," "loss," and "non-loss" (Cronbach's $\alpha=.66$ - .68) might be explained by our goal maintenance, negative escape, and active avoidance. The two items, "I am confident that I can meet my responsibilities and obligations" in their "non-loss" and "I am anxious that I will fall short of my responsibilities and obligations" in the "loss," are categorized as "goal maintenance" in our regulatory form. Also, the "goal maintenance" regulatory form should be closely related to their "non-gain" according to the item literally. The attempt for differentiating "I see myself as someone who is primarily striving to reach my ideal self" and "I see myself as someone who has trouble reaching my ideal self" (Summerville \& Roese, 2008, p. 251) likewise encouraged our discrimination of goal pursuit and goal maintenance, although "ought self" is expected to substitute the "ideal self" in the later item.

As shown in the above illustrations, the previous measurements can partially fit in the four regulatory forms, but not cover them all. Meanwhile, the lack of a complete subscale for the form of active avoidance becomes a major issue to evaluate the hypothesis of four regulatory forms. An alternative measurement based on the regulatory forms of goal pursuit, goal maintenance, negative escape, and active avoidance orientation should be developed in order to directly apply the concept. At present, future research in regulatory focus or regulatory fit studies is recommended to consider the framework of regulatory forms to select regulatory measurements and perform a factor analysis - for example, to recategorize the items. Such consideration could provide researchers with a clear standpoint, no matter what conceptualizations of regulatory focus they stand for.

\section{Comparing Regulatory Forms with Self-guide and Reference-point Definition}

The current study adopted the two dimensions, the objective reference and the regulatory action, in self-regulatory theories from Carver and Scheier (1981) and Higgins (1997) to build the four regulatory forms, goal pursuit, goal maintenance, negative avoidance, and active avoidance 
as our framework. Another interesting comparison is to Summerville and Roese's (2008) selfguide versus reference-point definitions, which might provide a coinciding framework.

Summerville and Roese (2008) indicated two distinct conceptualizations of regulatory focus: the self-guide definition and the reference-point definition, which could also form a two by two matrix although this concept was not fully discussed in their research. In Summerville and Roese's (2008) self-guide definition, the promotion focus emphasizes internal standards and is represented in terms of achieving personal aspirations, desires, and ambitions: namely, the ideal self-guide; in contrast, the prevention focus emphasizes social standards and is defined in terms of fulfilling duties, obligations, and responsibilities which are instilled by parents or other social based standards, namely the ought self-guide. Summerville and Roese (2008) suggested that duties and obligations are conveyed from parents or other authority figures. However, we challenge the claim that aspirations and ideals can also be established by parents or other significant figures. Therefore, the ideal-self versus ought-self dichotomy might not be flawless; thus, this self-guide definition could not clearly categorize promotion and prevention focus. On the other hand, Summerville and Roese's reference-point definition distinguishes promotion and prevention focuses on the two endstates of goal regulation, which is similar to the valence of the objective reference (i.e., desired versus undesired) in the current study. Furthermore, in their Study 2, the promotion-success (gain) and prevention-success (non-loss) subscales correlated significantly $(r=.41, p<.001)$; meanwhile, the promotion-failure (loss) and prevention-failure (non-gain) correlated substantially $(r=.53, p$ $<.001)$. It seems that these dimensions could hardly be orthogonal. It would be interesting to apply Summerville and Roese's (2008) self-guide definition and reference-point definition to a metaanalysis to examine the effect size of regulatory fit studies. Only based on our first glance, these two definitions cannot be fully applied to regulatory focus activations or regulatory fit evaluation. 


\section{Further Research and Limitation}

Active avoidance orientation. Existing measurements could not assess the active avoidance orientation because this orientation involves a dual concept: avoiding an undesired reference by approaching another desired one. The activation method - namely, the security-fulfillment task of the Maze Priming Technique (MPT), in which participants guide a mouse to escape from being captured by an owl via approaching the safe end of the maze-is expected to activate the "active avoidance" orientation. Study 2 demonstrated this orientation activated by security-fulfillment tasks might share some qualities with goal pursuit and negative escape. Further research is needed to reveal the nature of active avoidance.

Other moderators of regulatory fit effects. Because this study aims to explore and examine the regulatory forms rather than to perform another exhaustive review of prior studies and the consequences of regulatory fit (a review by Motyka et al. 2014), we did not seperate the fit effects by the detailed manipulation of such concerns as particular sources of focus (primed or chronic orientations), scopes (incidental or integral), routes (verbal, non-verbal, and mixed), or participants (students or non-student). These detailed moderating effects on regulatory fit could be found in the research of Motyka et al. (2014). However, further investigation of the moderators on specific regulatory forms is expected. 


\section{References}

Avnet, T., Laufer, D., \& Higgins, E. (2013). Are all experiences of fit created equal? Two paths to persuasion. Journal of Consumer Psychology, 23(3), 301-316. doi: http://dx.doi.org/10.1016/j.jcps.2012.10.011

Bentler, P. M. (1990). Comparative fit indexes in structural models. Psychological Bulletin, 107(2), 238-246. doi: 10.1037/0033-2909.107.2.238

Borenstein, M., Hedges, L. V., Higgins, J. P. T., \& Rothstein, H. R. (2009). Introduction to Meta-Analysis. UK: West Sussex: John Wiley and Sons, Ltd., Publication.

Brodscholl, J. C., Kober, H., \& Higgins, E. T. (2007). Stregies of self-regulation in goal attainment versus goal maintance. European Journal of Social Psychology, 37, 628-648.

Carver, C. S., \& Scheier, M. F. (1981). Attention and self-regulation: A control theory approach to human behavior. New York: Springer-Verlag.

Carver, C. S., \& Scheier, M. F. (2011). Self-regulatory of action and affect. In K. D. Vohs \& R. F. Baumeister (Eds.), Handbook of Self-Regulation: Research, Theory, and Applications (Second Edition ed., pp. 3 21). New Nork: The Guilford Press.

Carver, C. S., \& White, T. L. (1994). Behavioral inhibition, behavioral activation, and affective responses to impending reward and punishment: The BIS/BAS scales. Journal of Personality and Social Psychology, 67(2), 319-333. doi: 10.1037/0022-3514.67.2.319

Cesario, J., Grant, H., \& Higgins, E. (2004). Regulatory fit and persuasion: Transfer from “feeling right.” Journal of Personality and Social Psychology, 86(3), 388-404. doi: http://dx.doi.org/10.1037/0022-3514.86.3.388 
de Lange, M. A., \& van Knippenberg, A. (2009). To err is human: How regulatory focus and action orientation predict performance following errors. Journal of Experimental Social Psychology, 45(6), 1192-1199. doi: http://dx.doi.org/10.1016/j.jesp.2009.07.009

Erikson, E. H. (1963). Childhood and Society. New York: Norton.

Förster, J., \& Higgins, E. T. (2005). How global versus local perception fits regulatory focus. Psychological Science, 16(8), 631-636. doi: http://dx.doi.org/10.1111/j.14679280.2005.01586.x

Fellner, B., Holler, M., Kirchler, E., \& Schabmann, A. (2007). Regulatory focus scale (RFS): Development of a scale to record dispositional regulatory focus. Swiss Journal of Psychology, 66(2), 109-116. doi: 10.1024/1421-0185.66.2.109

Friedman, R. S., \& Förster, J. (2001). The effects of promotion and prevention cues on creativity. Journal of Personality and Social Psychology, 81(6), 1001-1013. doi: 10.1037/00223514.81.6.1001

Glass, B. D., Maddox, W., \& Markman, A. B. (2011). Regulatory fit effects on stimulus identification. Attention, Perception, \& Psychophysics, 73(3), 927-937. doi: http://dx.doi.org/10.3758/s13414-010-0068-4

Haws, K. L., Dholakia, U. M., \& Bearden, W. O. (2010). An assessment of chronic regulatory focus measures. Journal of Marketing Research, 47(5), 967-982. doi: 10.1509/jmkr.47.5.967

Hedges, L. V., \& Olkin, I. (1985). Statistical methods for meta-analysis: Academic Press New York. 
Hendrix, K. S., \& Hirt, E. R. (2009). Stressed out over possible failure: The role of regulatory fit on claimed self-handicapping. Journal of Experimental Social Psychology, 45(1), 51-59. doi: http://dx.doi.org/10.1016/j.jesp.2008.08.016

Higgins, E. T. (1987). Self-discrepancy: A theory relating self and affect. Psychological Review, 94(3), 319-340.

Higgins, E. T. (1997). Beyond pleasure and pain. American Psychologist, 52(12), 1280-1300.

Higgins, E. T. (2005). Value from regulatory fit. Current Directions in Psychological Science, 14(4), 209-213. doi: http://dx.doi.org/10.1111/j.0963-7214.2005.00366.x

Higgins, E. T. (2006). Value from hedonic experience and engagement. Psychological Review, 113(3), 439-460. doi: http://dx.doi.org/10.1037/0033-295X.113.3.439

Higgins, E. T., Bond, R. N., Klein, R., \& Strauman, T. (1986). Self-discrepancies and emotional vulnerability: How magnitude, accessibility, and type of discrepancy influence affect. Journal of Personality and Social Psychology, 51(1), 5-15. doi: 10.1037/0022-3514.51.1.5

Higgins, E. T., Cesario, J., Hagiwara, N., Spiegel, S., \& Pittman, T. (2010). Increasing or decreasing interest in activities: The role of regulatory fit. Journal of Personality and Social Psychology, 98(4), 559-572. doi: http://dx.doi.org/10.1037/a0018833

Higgins, E. T., Friedman, R. S., Harlow, R. E., Idson, L. C., Ayduk, O. N., \& Taylor, A. (2001). Achievement orientations from subjective histories of success: Promotion pride versus prevention pride. European Journal of Social Psychology, 31(1), 3-23. doi: 10.1002/ejsp.27

Higgins, E. T., Idson, L. C., Freitas, A. L., Spiegel, S., \& Molden, D. C. (2003). Transfer of value from fit. Journal of Personality and Social Psychology, 84(6), 1140-1153. doi: $10.1037 / 0022-3514.84 .6 .1140$ 
Higgins, E. T., Roney, C. J. R., Crowe, E., \& Hymes, C. (1994). Ideal versus ought predilections for approach and avoidance distinct self-regulatory systems. Journal of Personality and Social Psychology, 66(2), 276-286.

Higgins, E. T., Shah, J., \& Friedman, R. (1997). Emotional responses to goal attainment: Strength of regulatory focus as moderator. Journal of Personality and Social Psychology, 72(3), 515-525. doi: 10.1037/0022-3514.72.3.515

Idson, L. C., Liberman, N., \& Higgins, E. (2004). Imagining how you'd feel: The role of motivational experiences from regulatory fit. Personality and Social Psychology Bulletin, 30(7), 926-937. doi: http://dx.doi.org/10.1177/0146167204264334

Jin, S.-A. A. (2010). Does imposing a goal always improve exercise intentions in avatar-based exergames? The moderating role of interdependent self-construal on exercise intentions and self-presence. Cyberpsychology, Behavior, and Social Networking, 13(3), 335-339. doi: http://dx.doi.org/10.1089/cyber.2009.0186

Koenig, A. M., Cesario, J., Molden, D. C., Kosloff, S., \& Higgins, E. T. (2009). Incidental experiences of regulatory fit and the processing of persuasive appeals. Personality and Social Psychology Bulletin, 35(10), 1342-1355. doi: 10.1177/0146167209339076

Lee, A. Y., \& Aaker, J. L. (2004). Bringing the frame into focus: The influence of regulatory fit on processing fluency and persuasion. Journal of Personality and Social Psychology, 86(2), 205-218. doi: http://dx.doi.org/10.1037/0022-3514.86.2.205

Lockwood, P., Jordan, C. H., \& Kunda, Z. (2002). Motivation by positive or negative role models: Regulatory focus determines who will best inspire us. Journal of Personality and Social Psychology, 83(4), 854-864. 
Malaviya, P., \& Sternthal, B. (2009). Parity product features can enhance or dilute brand evaluation: The influence of goal orientation and presentation format. Journal of Consumer Research, 36(1), 112-121. doi: 10.1086/595717

Markus, H., \& Nurius, P. (1986). Possible selves. American Psychologist, 41, 954-969.

Marsh, H. W., Balla, J. R., \& Hau, K.-T. (1996). An evaluation of incremental fit indices: A clarification of mathematical and empirical properties. Advanced structural equation modeling: Issues and techniques, 315-353.

Memmert, D., Unkelbach, C., \& Ganns, S. (2010). The impact of regulatory fit on performance in an inattentional blindness paradigm. The Journal of General Psychology, 137(2), 129139.

Motyka, S., Grewal, D., Puccinelli, N. M., Roggeveen, A. L., Avnet, T., Daryanto, A., de Ruyter, K., Wetzels, M. (2014). Regulatory fit: A meta-analytic synthesis. Journal of Consumer Psychology, 24(3), 394-410. doi: http://dx.doi.org/10.1016/j.jcps.2013.11.004

Pham, M. T., \& Higgins, E. T. (Eds.). (2005). The state of the art and theoretical propositions. London: Routledge.

Plessner, H., Unkelbach, C., Memmert, D., Baltes, A., \& Kolb, A. (2009). Regulatory fit as a determinant of sport performance: How to succeed in a soccer penalty-shooting. Psychology of Sport and Exercise, 10(1), 108-115. doi: http://dx.doi.org/10.1016/j.psychsport.2008.02.001

Rogers, C. R. (1961). On becoming a person. Boston: Houghton Mifflin.

Rosenthal, R. (1979). The file drawer problem and tolerance for null results. Psychological bulletin, 86(3), 638-641. 
Rothman, A. J., Baldwin, A. S., Hertel, A. W., \& Fuglestad, P. T. (2011). Self-regulation and behavior change: Disentangling behavioral initiation and behaviral maintenance. In K. D. Vohs \& R. F. Baumeister (Eds.), Handbook of Self-Regulation: Research, Theory, and Applications (Second Edition ed., pp. 106-122). New Nork: The Guilford Press.

Sassenberg, K., Jonas, K. J., Shah, J. Y., \& Brazy, P. C. (2007). Why some groups just feel better: The regulatory fit of group power. Journal of Personality and Social Psychology, 92(2), 249-267. doi: http://dx.doi.org/10.1037/0022-3514.92.2.249

Schmidt, F. L., \& Hunter, J. E. (2014). Methods of meta-analysis: Correcting error and bias in research findings: Sage publications.

Shah, J., \& Higgins, E. T. (1997). Expectancy $\times$ value effects: Regulatory focus as determinant of magnitude and direction. Journal of Personality and Social Psychology, 73(3), 447-458. doi: $10.1037 / 0022-3514.73 .3 .447$

Shah, J., Higgins, T., \& Friedman, R. S. (1998). Performance incentives and means: How regulatory focus influences goal attainment. Journal of Personality and Social Psychology, 74(2), 285-293. doi: 10.1037/0022-3514.74.2.285

Sullivan, H. S. (1953). The collected works of Harvey Stack Sullivan. New York: Norton. Summerville, A., \& Roese, N. J. (2008). Self-report measures of individual differences in regulatory focus: A cautionary Note. Journal of research in personality, 42(1), 247-254. doi: 10.1016/j.jrp.2007.05.005

Szymanski, D. M., \& Henard, D. H. (2001). Customer satisfaction: A meta-analysis of the empirical evidence. Journal of the Academy of Marketing Science, 29(1), 16-35. doi: $10.1177 / 009207030102900102$ 
Vaughn, L. A., Hesse, S. J., Petkova, Z., \& Trudeau, L. (2009). “This story is right on”: The impact of regulatory fit on narrative engagement and persuasion. European Journal of Social Psychology, 39(3), 447-456. doi: http://dx.doi.org/10.1002/ejsp.570

Vaughn, L. A., Malik, J., Schwartz, S., Petkova, Z., \& Trudeau, L. (2006). Regulatory fit as input for stop rules. Journal of Personality and Social Psychology, 91(4), 601-611. doi: http://dx.doi.org/10.1037/0022-3514.91.4.601

Wang, J., \& Lee, A. Y. (2006). The role of regulatory focus in preference construction. Journal of Marketing Research, 43(1), 28-38. doi: http://dx.doi.org/10.1509/jmkr.43.1.28 